\title{
Policy-Making Indabas to Prevent "Not Listening": An Added Recommendation from the Life Esidimeni Tragedy
}

\author{
Samuel Ujewe and Werdie Van Staden
}

\subsection{Introduction}

Mental healthcare users, their families, health practitioners and government officials may fear the day that a health policy change turns out to be lethal. This happened in the Life Esidimeni tragedy during 9 months of 2016 and 2017 when more than 140 mental healthcare users died as a consequence of a policy change in a South African province. This chapter summarises and reflects on this tragedy as reported by the Health Ombudsman after a thorough official investigation [1].

One main finding captured as the heading of chapter 10 of the Ombud's report was a "failure to listen". However, none of the recommendations in the report advises that in the future "you should listen". For this reason and averting similar tragedies in the future, we additionally recommend a practical decision-making process by which to listen properly, specifically a policy-making indaba in an African version of values-based practice.

\subsection{The Life-Esidimeni Tragedy}

In what is arguably the most advanced healthcare system in sub-Saharan Africa, South Africa witnessed a foreseeable consequence of a loosely developed and poorly executed mental healthcare policy in the province of Gauteng. The policy ordered that about 1400 people be moved from Life Esidimeni mental healthcare

\footnotetext{
S. Ujewe

Canadian Institute for Genomics and Society, Toronto, ON, Canada

W. Van Staden $(\bowtie)$

Centre for Ethics and Philosophy of Health Sciences, University of

Pretoria, South Africa 
facilities to multiple care homes of non-governmental organisations (NGOs), resulting in 140 individuals dying over a course of 9 months between 2016 and 2017. Amidst horrific circumstances, the actual causes of death included thirst and hunger. An autopsy showed two lumps of hard plastic in the stomach of a patient who had died alone locked up in an outbuilding. Reports indicated furthermore that many patients were tied up and bundled up into buses and open pick-up vans in transporting them to their new locations.

The extent of the tragedy became only publically known after a complaint had been submitted to the Health Ombud. His report presented a deeply concerning situation revealing that all 27 NGOs to which the patients had been transferred operated under invalid licences and that all the deaths occurred under unlawful circumstances. Unsuitable conditions and incompetence at the NGOs were directly linked to the high number of deaths among transferred patients.

The Ombud's report showed that for every one death at the Life-Esidimeni care facilities, there were 19 deaths at the NGOs. This was underscoring that the NGOs were ill equipped to provide even in the basic needs of the patients they had received. To add to the problem, at the time of publishing the final Ombud's report, some of the patients who had been transferred could not be located by the Gauteng Directorate of Mental Health or their families and the provincial government could confirm the identities of only 48 of the patients who died. This meant that most of the families who had lost their loved ones had to wait months to access their bodies, and others did not even know whether their family members were still alive or dead.

The relocation of patients from the Life Esidimeni healthcare facilities to the NGOs was ushered by the Gauteng's government's decision to end its long standing contract with Life Esidimeni Healthcare network. The Gauteng Department of Health described the move as part of a process to deinstitutionalise patients and save money. However, the implementation proceeded prematurely with the receiving institutions accepting patients before they had signed service contracts. This meant that they went unpaid and were unable to provide adequately for the patients. They also received patients hastily without clinical records, treatments or health care plans. As the Ombud report also found, the transfers had been inadequately planned, chaotic, and rushed.

Before the transfers, the provincial directorate had been forewarned in a couple of urgent court challenges that the transfers would be unwise, flawed and put patients' lives at risk. The decision to move the patients out of Life Esidimeni facilities was made against expert advice from professional, user-movement and civil society stakeholders. The South African Society of Psychiatrists (SASOP) had noted the risks earlier in 2015 and warned that the transfer would be premature and highly risky. Likewise, other groups and families of the patients had been very concerned to such an extent that court litigation had been filed against the government. The court did not proceed with the legal case based on the government's assurance that patients would not be moved without consent from their families, and that the facilities and the healthcare would be similar to provisions at the Life-Esidimeni facilities. These promises were not kept as most affected families were not notified 
of, let alone involved in, the transfers. Some only learnt of the transfers and deaths months later.

The Ombud's investigation found that the decision to transfer the patients was a transgression of various laws and a violation of the constitutional human rights of the patients, including a lack of respect for the human dignity of the patients. The latter finding is ironic considering that "esidimeni" is an isiZulu word for "in dignity".

\subsection{The Limited Reach of Ombud's Recommendations}

Ombud's report concludes with various recommendations. Regarding the past events, these include disciplinary actions, corrective measures, further criminal investigations, legal proceedings, and financial compensation for surviving patients and families. Looking forward to averting the recurrence of similar events, the recommendations are mostly in human rights, regulatory and legal terms. For example, the recommendations are for a systematic and systemic review of human rights compliance and possible violations elsewhere in South Africa, the review of licensing processes, refinements of the relevant laws, and developing checks on legal and regulatory compliance.

Although these recommendations are no less important, their reach is inevitably limited-after all, lives have been lost and the clock cannot be turned back. We want to highlight another limitation, specifically regarding future policy-making. This is, the human rights and regulatory terms of the recommendations do not address one of the key findings of the Ombud, reported as the main finding of its chapter 10. This is "the failure to listen or to take advice", which was of "grave concern".

Instead, the decision to transfer the patients was said to be "final and nonnegotiable" and "the project had to be done". The government executive officer "would not listen" and "left no room for engagement". Many employees felt "powerless" and having to implement and deliver the outcome of a project in which they "did not believe", with an outcome they thought "impossible to achieve" and "not do-able within the short time frame". Personnel said they did not "shape the project's evolution", "were not participants in the decision-making processes", and that it was "tough" and "very stressful" to implement. The report alludes to "a general climate and culture of fear and disempowerment" in which families and health workers felt "not being listened to" and "being left out".

The report criticises that the planning process for making the transfers was largely limited to the government officials, without "involving communities and civil society organisations in any credible manner." The failure to listen persisted even when challenged by legal action, going against the warnings and advice of "widespread professional, expert and civil society stakeholders"-warnings that "have sadly come true". 


\subsection{The Indaba for Listening Properly in Policy-Making}

To avert a similar tragedy, we advocate that all stakeholders implied in the formulation and execution of health policy should listen properly to each other. This requirement should extend beyond the reach of rights, laws and regulations, or recommendations in these terms as made in Ombud's report. By analogy, whether and how spouses love each other should generally exceed the reach of matrimonial rights, laws and regulations notwithstanding that these may be relevant potentially.

This means all stakeholders implied in the formulation and execution of health policy should listen properly to each other, not merely in terms of legal and regulatory prescriptions and rights. Although these values may be potentially important, listening to each other would only be done properly when also "listening to" other values of the stakeholders.

An indaba in an African version of values-based practice (A-VBP) is a practical process for stakeholders to listen properly to each other [2]. The isi-Zulu word "indaba" captures a process common in sub-Saharan Africa, described inclusively as a meeting to discuss a matter where individuals and communities have a voice in generating a common story to tell about a matter of concern. Chapter 21 of this volume, titled "Thinking Too Much: A Clash of Legitimate Values in Clinical Practice Calls for an Indaba Guided by African Values-based Practice" illustrates a clinical indaba. An indaba is similarly suited to generate a common story in policy-making.

A policy-making indaba in A-VBP would comprise a meeting during which all the stakeholders implied in the formulation and execution of a health policy listen properly to each other. Indaba participants would listen to what matters to fellow participants, getting to know and understand their values. As described for a clinical indaba in chapter 21 of this volume, listening properly to a fellow participant on what he, she, a community or a society value does not mean that fellow participants have to adopt that value, nor that someone has to compromise or relinquish theirs [3, 4]. Rather, the policy-making indaba would seek to generate a shared story that accounts creatively for differences between values. A key question for leading [3] the policymaking indaba with leadership skills in the Life-Esidimeni situation could for example have been: how may (the story of) the resulting policy account for the differences between values of the stakeholders without dismissing or changing anyone's values?

Policy-making indabas in mental health would require that actions of care providers and governing officials create spaces for sustained engagement with the patients, to the extent possible, and their families and/or communities. In the Life Esidimeni case, for instance, the government's decision to terminate the contract or change the nature of care given to the patients should not have been actioned without a family and community indaba. Following this, another indaba to determine where and how to transfer patients should have been undertaken. These indabas could have established common grounds between the government, healthcare providers and the patients' families and communities regarding the conditions of the patients and the nature of care they receive, while also seeking creative ways to account for differences of values among them. 
Listening properly to each other in a policy-making indaba may be implored by the human right by which all people are bestowed with dignity, whereby human stakeholders should listen properly to each other. Another perhaps more persuasive reason in an African context is found in an African way of living one's personhood [5]. Personhood in an African context has largely been described in terms of Ubuntu. The idea of Ubuntu situates every individual person within a community or society as inevitably existing in relationship with others around them. Ubuntu also recognises the dependency of a community on its individuals [6]. Thus, a person is a person through other persons, where the individual person is inevitably involved in varied social and moral duties and commitments that focus on the wellbeing of others around them [7]. This means that "the existence of an individual—his/her livelihood, activities, achievements, and burdens-is predicated on those of other individuals, who together share a common social space" [8]. The converse also pertains: the existence of a community is predicated on the existence of its individuals. The relational coexistence derives from the African communal structure that emphasises imperatives for social relationship and vital interdependencies [6,9]. The ethic, thus, emphasises reciprocal and dual responsibility [9], where individuals are drawn by shared-values towards obligations to each other and to the communities where they belong as well as a responsibility of a community towards anyone of its members.

The nature of African communal and relational personhood means that family or communal participation is crucial in mental health policy-making. Given the social embeddedness of personhood in African settings, the person suffering from a mental disorder would be considered as being compromised in or even losing his/her personhood, owing to the isolation and impaired social functioning commonly associated with mental disorder. When the affected person becomes less a part of his/her network of relationships, the situation is of crucial social consequence, not only for the person affected, but also for their families, communities and entire network of relationships.

The decision to end the care services of Life Esidimeni was initiated through a process that did not recognise the communal embeddedness of their personhood. The emphasis on the financial dimension further buttresses the lack of acknowledgement of the patients' place within their communities, especially by shutting out third-party participation in the process. Instead, a prior indaba process in the Life Esidimeni case could have ensured that decisions recognised these social interdependencies of personhood. Through an indaba, finding harmony among the differing perspectives in the decision-making process might have averted the tragedy that ensued.

\subsection{Conclusions}

A policy-making indaba within A-VBP provides a practical process in which all stakeholders implied in the formulation and execution of health policy may listen properly to each other. Listening properly to each other entails that the differing values are accounted for in the resulting policy, which is in effect contracting 
co-authorship and co-responsibility for a health policy. Accordingly, policy-makers are not merely governmental officials and politicians but are extended to all stakeholders implied in the formulation and execution of a health policy. Especially familiar in an African context, this extension may be impelled by an African communal and relational way of living personhood, whereby reciprocal responsibility is taken up for each other among individuals as well as between a community and its individual members $[5,6,9]$.

\section{References}

1. Makgopa MW. The report into the circumstances surrounding the deaths of mentally ill patients: Gauteng province. Republic of South Africa: Health Ombud; 2017.

2. Van Staden CW, Fulford KWM. The indaba in African values-based practice: respecting diversity of values without ethical relativism or individual liberalism. In: Sadler JZ, van Staden CW, Fulford KWM, editors. Oxford handbook of psychiatric ethics. Oxford: Oxford University Press; 2015.

3. Van Staden CW. Spiritual and other diversities at the heart of invigorating leadership: a South African spark. Int J Leadersh Public Serv. 2010;6:73-7.

4. Van Staden CW. Stuck in the past or heading for flourishing people in diversity. S Afr J Psychiatry. 2010;16:4-6.

5. Van Staden CW. African approaches to an enriched ethics of person-centred health practice. Int J Pers Cent Med. 2011;1:11-7.

6. Crepaz-Keay D, Fulford KWM, Van Staden CW. Putting both a person and people first: interdependence, values-based practice and African Batho Pele as resources for co-production in mental health. In: Sadler JZ, van Staden CW, Fulford KWM, editors. Oxford handbook of psychiatric ethics. Oxford: Oxford University Press; 2015.

7. Munyaka M, Motlhabi M. Ubuntu and its socio-moral significance. In: Murove MF, editor. African ethics: an anthology of comparative and applied ethic. Scottsville: University of KwaZulu-Natal Press; 2009.

8. Ujewe SJ. Just health care in Nigeria - the foundations for an African ethical framework. Preston: University of Central Lancashire; 2016. p. 124-5.

9. Gyekye K. Tradition and modernity: philosophical reflections on the African experience. Oxford: Oxford University Press; 1997.

Open Access This chapter is licensed under the terms of the Creative Commons Attribution 4.0 International License (http://creativecommons.org/licenses/by/4.0/), which permits use, sharing, adaptation, distribution and reproduction in any medium or format, as long as you give appropriate credit to the original author(s) and the source, provide a link to the Creative Commons license and indicate if changes were made.

The images or other third party material in this chapter are included in the chapter's Creative Commons license, unless indicated otherwise in a credit line to the material. If material is not included in the chapter's Creative Commons license and your intended use is not permitted by statutory regulation or exceeds the permitted use, you will need to obtain permission directly from the copyright holder.

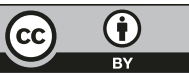

